\title{
METHODS OF TRAINING SIMULATORS DEVELOPMENT IN ASPECT OF INCREASING EFFICIENCY AND SAFETY PRODUCTION
}

\author{
Gubin Vladimir Viacheslavovich \\ $\mathrm{PhD}$ in eng. sc., assistant lecturer \\ Department of technological process automation and production \\ Saint-Petersburg Mining University, Russia \\ Fedorova EImira Rafaelevna \\ $\mathrm{PhD}$ in eng. sc., assistant lecturer \\ Department of technological process automation and production \\ Saint-Petersburg Mining University, Russia \\ Darin Aleksey Aleksandrovich \\ $\mathrm{PhD}$ in eng. sc., associate professor \\ Department of technological process automation and production \\ Saint-Petersburg Mining University, Russia
}

\begin{abstract}
.
In the Russian Federation, the traditional mechanisms of inspection control are changing and industrial safety measures are being modernized.

Operator mistakes are one of the most common causes of industrial accidents. The practice of the introduction of interactive training complexes indicates formation of behavior skills in normal and non-standard (emergency) modes of installations work during the training, thereby reducing the the possibility of accidents caused by personnel and, as a result, increases the safety and efficiency of production.

The article is devoted to the development of technological processes operators simulators used to train operational personnel skills of technological processes management of industrial enterprises. Describes the main requirements to the computer equipment and the development of their mathematical support. The basic concepts and methods of analytical and simulation modeling of technological systems are given.

The principles of application of neural networks as one of the most promising methods of complex technological processes modeling in the development of control systems and simulators of industrial plants are considered in detail.

Various aspects of process modeling and the main advantages of using training simulators to improve production efficiency are considered.
\end{abstract}


Keywords: industrial simulator, operator training simulator (OTS), process simulator, simulation model, neural network, production safety.

Cite this Article: Gubin Vladimir Viacheslavovich, Fedorova Elmira Rafaelevna and Darin Aleksey Aleksandrovich, Methods of Training Simulators Development in Aspect of Increasing Efficiency and Safety Production, International Journal of Management, 10 (2), 2019, pp. 117-121.

http://iaeme.com/Home/issue/IJM?Volume $=10 \&$ Issue $=2$

\section{INTRODUCTION}

It is well known that computer training first appeared in such areas as aviation and astronautics, ship driving and nuclear power. This is due to the huge risk to human life and safety and strict requirements of legislation in the field of training and certification of workers in these industries [1]. Qualitative improvement of the system of information support of subsoil use, monitoring and control through the development of information technologies, including introduction of automated control and regulation systems is one of the strategic objectives of Russian enterprises $[2,3]$.

Training of professionals working on technological installations is a complex and multistage process that requires the use of modern tools and techniques implemented in educational programs of specialized universities and programs of additional professional education. As well as traditional learning system, examples of modern e-learning management tools are LMS systems such as Moodle and Canvas. Training materials for these systems are prepared by both qualified teachers and entire companies, for example, Cisco Systems Corporation. Various systems of video communication and web-conferences are used to organize remote communication between specialists and students [4].

\subsection{Technologies and development features}

All training systems are characterized by: reproduction of the simulated object dynamics, simulation of measurement and control of the object, the reproduction of the instrument part of the human-machine interface, etc.

From the point of view of construction of the simulator model, the work of continuous objects of chemical-technological type can be described by means of mechanism simulations of hydraulics, mass and heat transfer, chemical kinetics and other processes [5, 6, 7]. Most of these objects are spatially concentrated groups of technological equipment, united by material and energy flows and operating in modes close to equilibrium. Under these conditions, the main task of the operator is to maintain this balance, recognizing deviations and timely stopping their undesirable consequences.

In the simulator models of technological processes (TP) there are no components associated with the reproduction of non-selective signals, and the processes, despite the extremely diverse nature, are described by the general equations of state, hydraulics, material and energy balance, etc.

Also operator control environments of various TP are similar. Not by chance that the manufacturers of computer control systems (DCS, PLC and SCADA-systems) supply their products to a variety of continuous production - from metallurgy to food industry.

The operator interface in TP is simple in structure and typical for different objects. With modern information technology, when simulators are almost fully compatible with real control systems, the construction of an adequate simulator operator interface becomes a real task. 
The absence of the need of instrument information modelling and reproduce expensive interfaces, allows us to consider the construction of simulators for TP operators as the task of developing a universal software and hardware platform and a set of special training models [8].

The basis of the functioning of the computer simulator is simulation mathematical models of the process and the algorithm of the simulator. Simulation control systems are based on the principles of the theory of learning pattern recognition and are designed to "teach" the machine to simulate the actions of the "best specialists".

The main difficulty in the implementation of the simulator is the development of mathematical and software. This is due to the wide variety of physical and chemical transformations occurring in various metallurgical units and technological processes.

As a result, it becomes impossible to create a universal mathematical model for metallurgical facilities and, as a rule, it is necessary to develop applied mathematical and software for a specific task $[8,9]$.

Mathematical modeling for studing of systems functioning process characteristics can be divided into analytical, simulation and combined [10].

Analytical modeling is characterized by the fact that the process of functioning of the system elements (physical and chemical transformations, charging, release, heat and mass transfer) is described in the form of some functional relations (algebraic, differential, finite-difference) or logical conditions.

The task of simulation modeling is to build a mathematical model of the control object on the basis of advanced experience of the operator, followed by the use of this model in the control system.

In simulation modeling the elementary phenomena that make up the process are simulated, while maintaining their logical structure and sequence over time.

The main advantage of simulation modeling over analytical modeling is the ability to solve more complex problems. Simulation models can take into account the following factors: the presence of discrete and continuous elements, nonlinear characteristics of the system elements, numerous random effects.

There are a number of methods for creating such models, which are based on:

- Physical and chemical transformations, material and thermal balances;

- Experimental and statistical methods;

- Theories of artificial neural networks.

Based on the analysis of the main physical and chemical transformations characterizing a particular process, dynamic models are created. This approach is used when the physical laws are known and mathematical models are based on theoretical descriptions, which allows to take into account the quantitative and qualitative laws of the process. Such model can be used for optimization of TP, apparatus and process control system.

The use of models based on material and thermal balances is possible in the planning of production, in the development of technological regulations and feasibility studies of projects.

The method of statistical tests has the greatest effect of its application in the study of complex systems, the functioning of which is significantly influenced by random factors. In cases of insufficient information about the process and complexity of the resulting theoretical approach of mathematical description in solving the problem of operational management is more appropriate to use simple structurally models based on formal mathematical expressions (polynomials), which are based on experimental and static methods of object research and processing of observational data. 
Control systems based on artificial neural networks $(N N)$ - one of the clearest examples of modern technologies based on the bionic approach, when the principles of functioning and control of living organisms are effectively used to create a new generation of control systems of technological and mechatronic systems.

Neural networks are trained by the system developer on specific examples. During training, the developer enters information about the input and the corresponding (desired) output signals. A special network configuration program automatically selects the weights for all neurons in such a way as to achieve the desired conformity for different input data. Thus, the configured network is ready to solve new problems for other combinations of input signals.

The main feature of the neural network method is that the developer should not program a clear algorithm for solving problems, but only set the input and output data for training.

The problems of neural networks applying in practice are associated with the choice of the type of neurons (i.e., nonlinear function), the number of layers and network structure to solve a specific problem with the required accuracy.

Building a neural network model of the process consists of four stages: pre-processing of data; selection of network structure; optimization of parameters and solution adequacy verification.

The use of neural network methods in create a model of the process will allow to correct the parameters of the model depending on the changing conditions and thus increase the accuracy of the simulation. Artificial neural networks are a good tool for solving modeling problems, which has greater accuracy and adequacy, but only in cases where there is a large amount of experimental data taken in a relatively short period of time.

Regardless of the modeling method, it is advisable to use mathematical models of varying complexity at different stages of training, from the student to the operator of the real technological process [11].

During the mathematical and software developing it is necessary to consider the following main factors:

- The mathematical model of the studied process should provide the possibility of entering of control actions during the process the used in the management of the real process;

- The mathematical model should include only those parameters that are available for continuous automatic control at this facility;

- The reaction to the control actions of the mathematical model and the simulator should be identical to the reaction of the real object;

- During creating a model, it is necessary to predict the change of the controlled parameter in time;

- During the creation of mathematical models one should consider the possibility of obtaining additional information on changing the basic parameters;

\section{CONCLUSION}

The analysis of the basic principles and technologies of creating simulators and the nuances of their application in order to increase the efficiency and safety of production, allowed to identify the main possible advantages of their use as: the ability to repeatedly reproduce the "working" situation without the cost of resources of real production and the creation of man-made threats; the ability to improve the quality of training by simulating real-world technological situations and modes; possibility of complete set selection and price; reduction of capital costs for operator training. 


\section{REFERENCES}

[1] Ferapontov A.V. Principles of the organization of risk-based supervision of OPO / Occupational Safety in Industry, 2010. No. 6,. - pp. 4-7.

[2] Sizyakov V.M., Bazhin V.Yu., Selishcheva T. A., Vlasov A. A. The Role of the state in the sphere of innovative activity of nonferrous metallurgy enterprises of Russia / Metallurgist, 2014. No. 1. - pp. 1-7.

[3] Development strategy of the mineral resource base of the Russian Federation to 2035: the RF Government decree of 22 December 2018. No. 2914. - 31 p.

[4] Miss. Smita B. Garde, Prof. S.L.Kotgire, Coalmine Safety System with Zigbee Specification, International Journal of Electronics and Communication Engineering \& Technology (IJECET), Volume 4, Issue 2, March - April, 2013, pp. 504-512

[5] Katuntsov E.V., Kultan J, Makhovikov A.B. Application of Electronic Learning Tools for Training of Specialists in the Field of Information Technologies for Enterprises of Mineral Resources Sector / Journal of Mining Institute, 2017. Vol. 226. -pp. 503-508.

[6] A. Shanmuganathan, N. M. Sivaram and P. Shanmughasundaram, Discomfort Due To Work Environment and Safety Factors Among Workers In Foundry Industry, International Journal of Civil Engineering and Technology, 8(8), 2017, pp. 820-826.

[7] Snehal K.Paliwal, Mrs. Shaila P. Kharde, Robinson, Reagan Nnabio and Kpabep, Charity M., A Review On Data Acquisition and Control System for Industrial Automation Application. International Journal of Electronics and Communication Engineering \& Technology, 6(7), 2015, pp. 26-30.

[8] Petuhov A.A., Darin A.A., Telyakov A.A. Processing of ferromanganese nodules of the Pacific Ocean. / Metallurgist, 2017. Vol. 61, No. 5-6. -pp 439-443.

[9] Beloglazov I. I., Petrov P. A., Martynov S. A. Application of Production Processes Control Algorithm Using Adaptive Control Systemg / International Russian Automation Conference, RusAutoCon, 2018. Vol 1. - pp. 1 - 4.

[10] N. Tarun and N. Lokeshwaran, A Case Study on Assessing Energy Efficiency of Existing Residential Building and Recommendations Ensuring Green Efficiency in Building Construction Projects. International Journal of Civil Engineering and Technology, 8(3), 2017, pp. 921-927.

[11] Dozortsev V. M. Training of operators of technological processes on the basis of computer simulators / Devices and control systems, 1999. No. 8. -pp. 61 - 70.

[12] Koteleva H. I., Shablovsky I. E., Koshkin A.V. Computer simulators for training operators of technological processes in the oil and gas industry: analysis of existing solutions and ways to improve them / Journal of Mining Institute, 2011. Vol. 192. - pp. 212-215.

[13] Pupkov K. A. Egupov N. D. Methods of robust, neuro-fuzzy and adaptive control / Tutorial. Vol. 4: optimization Theory, automatic control systems - M.: MGTU im. N. Eh. Bauman, 2004. - $742 \mathrm{p}$.

[14] Samarth Ramprasad. K and Dr. Prabhat Kumar, 3 Factor - Hot (Human, Organizational and (Technical) Model for Construction Safety Culture. International Journal of Civil Engineering and Technology, 9(8), 2018, pp. 530-541.

[15] Osipova V. A., Denikina G. B. Improving the efficiency of training of technological process operators based on computer simulators / Systems. Methods. Technologies, 2011. No. 3. - pp. 106-114. 